\title{
DESIGNING AND DEVELOPMENT OF ECOFRIENDLY ELECTRIC SOLAR CAR
}

\author{
Kanwar J.S Gill ${ }^{1}$, Ravinder Goyal ${ }^{2}$, Kulvir Singh $^{3}$, Champak Gogoi ${ }^{4}$, \\ Shaikh Saqib ${ }^{4}$
}

1 ( Head, Department of Mechanical Engineering, Gulzar Group of Institutes,Ludhiana,PTU,India.)

2. (Head, Department of Automobile Engineering, Gulzar Group of Institutes,Ludhiana,PTU,India.)

3. (Asst.Prof., Department of Automobile Engineering, Gulzar Group of Institutes,Ludhiana,PTU,India.)

4. (Students, Department of Mechanical Engineering, Gulzar Group of Institutes,Ludhiana,PTU,India.)

\begin{abstract}
As the earth's population is growing day by day and the earth might have some limit to sustain the overgrowth of population. According to the sources the world's population will grow to two to three times the present number in coming century. The most important question arises is that, whether there are sufficient natural resources to sustain the increased population? Here energy is the main issue. In today's era companies dealing with fossil fuels are not able to cope up with the increased demand. On one end new vehicles are dominating the transport medium and on the other end fuel is dominating the vehicles. Due to which limited natural resources are quashed by the oil producing companies to satisfy the increase in demand of fuel, which in turn will lead us to an uncertain future with scarcity of fuel and other resources. So it gives us a clear picture that energy consumption, especially oil shall not sustain to a much long lasting limit. On the contrary these fuels give rise to global warming, so it becomes necessary to find out an alternate for exhausting natural resource and to decrease the global warming issues. But why we should find out an alternative for fuels when an alternate is in front of our eyes which are very much cost effective and an endless source of energy. As there is an effective energy version available, a transition to this energy based economy which is self sufficient to maintain the increased demand in today's era is possible and this effective energy version is "Solar Energy". This paper describes the work done in designing and fabrication of gearless drive electric solar car which is fabricated for making clean and green environment, not only limited to this feature this vehicle can be used as multiutility vehicle.
\end{abstract}

Keywords - Solar, Gearless, Electric car, Multiutility, designed, fabricated.

\section{INTRODUCTION}

To save the precious environment one of the major steps taken is development of solar powered run vehicle which not only shall save us only but will save our coming off springs, which has been disturbed day to day by the high level increase in the pollution being emitted by all the vehicles having internal combustion engines. Not only limited to vehicles pollution is also emitted by industries.

While the solar vehicle is based on the concept of utilizing solar energy in to the mechanical energy, the design of this vehicle allows for fewer moving parts which lead to higher efficiency in terms of mileage and reliability. As we all are in a need for eco-friendly environment which is a basic necessity not only for us but for our coming next generations also. Hence by gaining a lot from the past polluted environment design and development of solar car was a mandatory step. In lieu of that solar vehicle was developed having many features like one can use as a passenger vehicle, as an load carrier also, even teenagers can also use it who are not having licence to run an Internal combustion engine powered vehicles. One can have its use in hospitals also where zero noise zones are there. To reduce the weight of the vehicle rectangular hollow pipes are considered.

\section{A. RESEARCH OBJECTIVE}

As we all know that sunlight is one of the major energy source of sufficient available energy which we can utilize and implement for maximum day to day application work. As we all know that we can produce electricity through solar energy, with this theme we aimed to develop soar car. Firstly we thought to implement this concept on small toy car and later on we extended our work on designing and developing of an actual car 
powered by the solar energy which is both cost effective and eco friendly. We also intend to solve the problem of voltage fluctuation.

\section{B. GLOBAL WARMING}

As the global warming increasing day by day we have to see the damage of our ecology and also we have to see the disappearance part of the rare species found on this earth as this will lead to destabilization of our natural resources upon which population is dependent. Concern part is also the migration of species from warm sea area to colder sea area where they will destroy the other species also. We have seen these types of changes in Mediterranean Sea, where we have observed barracudas from the Red Sea. [1-2]

More attention has to be given on ecological disaster, as these disaster causes very high limit of unrepareable damage to the ecology as compared to natural disaster. South pacific region has been affected by dryness, tornadoes due to global warming phenomena such as "El Niño,"

Another major side effect of global warming is the melting of polar ice which in turns raises the level of sea and causes permanent overflow in the coastal regions and in some parts of the neighboring countries also. Boldly speaking, its water vapors' which are directly responsible in large amount for creating green house gases and it's not the human being which creates direct effect on the environment. But even a light increase in the level of carbon dioxide (CO2) will eventually give rise to increase in the earth's temperature level.

There are two major reasons for this and the first reason lies here: The major composition of earths gases are oxygen and nitrogen and neither both of them contribute to green house gas effect, although there concentration is very much large as compared to green house gases..The fact lies here is that neither oxygen or nitrogen has got more than two atoms per molecule due to which both the gases lack Internal vibrational modes and actually molecules having more than two atoms should have, like water and carbon dioxide gas has got these modes and it's the natural tendency of such gases to directly absorb and again radiate the infrared type of radiations which in turn is directly responsible for creating green house effect.

The second most reason is the biggest reasons and it is: The lying power of carbon dioxide in the atmosphere is very long; it can lay up to an extent of more than a century. Depending upon the local atmospheric condition the water vapors may either condense or evaporates accordingly. Due to this very reason water vapor has got the tendency to adjust themselves according to the available atmospheric status, such that when the energy flows from the sun, it again reflects back from the earth and maintains a balance which is needed for the survival of nature. Due to this factor the level of carbon dioxide remains at a balanced state whole around and acts as a controlling part but not acts as an opposing part. If the level of carbon dioxide is large in atmosphere it means that more balance will occur in the regions having higher temperature level and higher water vapor levels.

\section{ELECTRIC VEHICLES}

Electric motor is used for every electrically run vehicles for traction purpose and for energy source we make use of batteries, capacitors or fuel cells. [3-4]. There are number of advantages of electric vehicles as compared to traditionally use of Internal Combustion engines like there is zero emission, increase in efficiency, no use of petrol/diesel, zero noise and quiet smooth operation. Fundamental principal and operation of both Electric vehicles and Internal Combustion engine vehicles are same. But there are some differences, like fuel tank vs. battery bank, Internal Combustion engine vs. Electric motor and other transmission modules.

\section{PERFORMANCE OF ELECTRIC VEHICLES}

Basic principles of physics are taken into consideration, specially, Newton's second law of motion for which this vehicle has been designed. And we all know that any object having acceleration is directly proportional to the total force which is exerted upon it. Due to this any object gains acceleration even though when net force acting on it is not equal to zero. As it is the resultant force which governs the flow of motion although there are several other forces acting on the vehicle at the same time and this has to obey the Newton's second law of motion. The needed amount of force to propel the vehicle is delivered by its propulsion unit. Due to this force the vehicle overcomes the resisting force like opposing air, self weight, frictional force, gravity, etc. As it is well known fact that the acceleration of the vehicle depends upon the factors like: Condition of the surface of the road, 
aerodynamics of the body, whole weight of the vehicle and last but not the least the exact amount of power produced and delivered by the its power producing unit.

After doing complete analysis of the forced acting upon the vehicle we can find out the exact motion of any vehicle. Let $(\mathbf{F t})$ be the tractive force which helps the vehicle to push forward the vehicle even though there is resistance acting between the surface of the road and tires of the vehicle. This force is actually developed by the Engine itself which is also known as power plant and then this force is being transmitted to the final drive line. Resistive force tends to stop the vehicle and hence it retards the motion also. Some types of resistive forces are: resistance produced due to rolling, Drag produced in vehicle due to aerodynamic conditions and while going up a hill.

\section{A. Traction Motor Characteristics}

When we calculate the driving performance we have to account for vehicles, maximum speed, time to accelerate and more over one of the important factor is its gradability. So as to meet the performance of electric vehicles we have to consider proper design of drive train, motor power and transmission parameters. All these design parametric depends upon speed and power characteristics of the motor. In case of electric vehicles primary consideration are proper motor torque rating and transmission characteristics.[5]

And the design criteria of all the above given concepts directly depends upon the torque characteristics of the tractive motor.Figure-1 shows the characteristics of electric motor having variable speed. The motor has a constant torque as shown in its low speed region. On the other hand the motor has a constant power in its high speed region, which is higher than the base speed. This is represented by "x", known as speed ratio, which can be defined as the ratio of maximum speed to the base speed of the tractive motor.

When we operate the motor at low speed then the supply of the voltage increases through the Electronic control unit, but the flux is kept at constant value. At this juncture of base speed the voltage of the tractive motor reaches the source voltage. And after the base speed the Electronic control unit keeps the motor voltage constant and due to this the flux weakens and drops out in the shape of a hyperbola when the speed is increased. And the torque also starts dropping down in the form of a parabola when speed is increased.

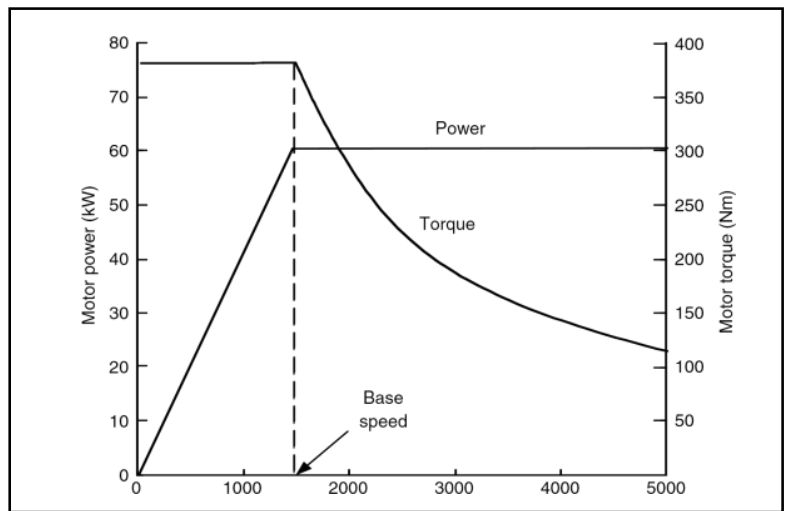

"Fig. 1 Typical variable-speed electric motor characteristics"

\section{B .TRACTIVE EFFORT AND TRANSMISSION REQUIREMENT:}

The tractive effort developed by a traction motor on driven wheels and the vehicle speed are expressed as

$$
F_{t}=\frac{T_{m} i_{g} i_{0} \eta_{t}}{r_{d}}
$$


And

$$
V=\frac{\pi \mathrm{N}_{m} r_{d}}{30 i_{g} i_{0}}(\mathrm{~m} / \mathrm{s}),
$$

where $\mathbf{T}_{\mathbf{m}}$ and $\mathbf{N}_{\mathrm{m}}$ are the motor torque output and speed in rpm, respectively, $\mathbf{i}_{\mathrm{g}}$ is the gear ratio of transmission, $\mathbf{i}_{0}$ is the gear ratio of final drive, $\square_{t}$ is the efficiency of the whole driveline from the motor to the driven wheels, and $\mathbf{r}_{\mathrm{d}}$ is the radius of the drive wheels.

The use of a multi gear or single-gear transmission depends mostly on the motor speed-torque characteristics. That is, at a given rated motor power, if the motor has a long constant power region, a single-gear transmission would be sufficient for a high tractive effort at low speeds.[6] Otherwise, a multi gear (more than two gears) transmission has to be used.

Due to the torque speed criteria of electric motors these motors are capable enough to have their terrific use in electric vehicles as these motors have the ability to deliver very high torque needed during the starting period of time. Selected designed should be taken in case of motors, like if there is a need for 10 Horsepower motor then here 15 horsepower will not be suitable and vice versa as horsepower directly fluctuates in accordance to ampere and voltage.[7].

And one should not compare an Internal combustion engine with Electric motor because internal combustion engines are rated in accordance to their highest peak horsepower delivered under a given set of load, where as an electric motor is manufactured and designed for continuous rating under a given set of load. Some of the commonly used electric motors are Direct current motors, Direct current shunt motors, Pulse modulated Permanent magnet motors.

\section{BENEFITS OF ELECTRIC VEHICLES OVER OTHERS.}

[1] If you are a consumer or a customer one can save a lot on fuel expenses. However, there are so many different reasons why you should invest in an electric car in the modern day of technology.

[2] No Requirement of gas: These cars are basically charged by the electricity you provide, meaning you don't need to buy any gas ever again. Driving fuel based cars can burn a hole in your pocket as prices of fuel have gone all time high. With electric cars, this cost can be avoided as an average

[3] Savings: These vehicles can be runn for very cheap prices, and many new cars will offer great incentives for you to get money back from the government for going green. Electric cars can also be a great way to save money in your own life.

[4] No Emissions: Electric cars are 100 percent eco-friendly as they run on electrically powered engines. It does not emit toxic gases or smoke in the environment as it runs on clean energy source. They are even better than hybrid cars as hybrids running on gas produce emissions. You'll be contributing to a healthy and green climate.

[5] Popularity: EV's are growing in popularity. With popularity comes all new types of cars being put on the market that are each unique, providing you with a wealth of choices moving forward.

[6] Safe to Drive: Electric cars undergo same fitness and testing procedures test as other fuel powered cars. In case an accident occurs, one can expect airbags to open up and electricity supply to cut from battery. This can prevent you and other passengers in the car from serious injuries.

[7] Cost Effective: Earlier, owing an electric car would cost a bomb. But with more technological advancements, both cost and maintenance have gone down. The mass production of batteries and available tax incentives has further brought down the cost, thus, making it much more cost effective.

[8] Low Maintenance cost: These cars are running on electric motors so there is no need to lubricate the engine by pouring engine oils in them. Other expenses like engine services have also gone down which in turn saves a lot. 


\section{SPECIFICATIONS}

Table-1 Vehicle Specification

\begin{tabular}{|c|l|c|c|l|c|}
\hline S.No & \multicolumn{1}{|c|}{ Specifications } & Values & S.No & \multicolumn{1}{c|}{ Specifications } & Values \\
\hline 1. & Length of vehicle & $200 \mathrm{~mm}$ & 7. & Aerodynamic drag coefficient & 0.3 \\
\hline 2. & Breadth of vehicle & 920 & 8. & Weight of vehicle & $212 \mathrm{~kg}$ \\
\hline 3. & Weight of vehicle & $120 \mathrm{~kg}$ & 9. & Weight handling capacity & $1100 \mathrm{~kg}$ \\
\hline 4. & Load carrying capacity & $900 \mathrm{~kg}$ & 10. & Acc. Time (from 0 to $25 \mathrm{~km} / \mathrm{hr}$ ) & $8+/-1 \mathrm{~s}$ \\
\hline 5. & Rolling resistant Co-efficient & 0.01 & 11. & Maximum speed & $40 \mathrm{~km} / \mathrm{hr}$ \\
\hline 6. & Ground Clearance & $350 \mathrm{~mm}$ & & & \\
\hline
\end{tabular}

Table-2 Battery specifications

\begin{tabular}{|c|l|c|c|l|c|}
\hline S.No & \multicolumn{1}{|c|}{ Specifications } & Values & S.No & \multicolumn{1}{|c|}{ Specifications } & Values \\
\hline 1. & Batteries 15 plate & $4 \mathrm{No}$ & 4. & Battery pack voltage & 48 Volts \\
\hline 2. & Weight of batteries & $92 \mathrm{~kg}$ & 5. & Single battery voltage & 12 Volts \\
\hline 3. & Battery capacity & $100 \mathrm{Amp}$. & & & \\
\hline
\end{tabular}

Table-3 Motor Specification

\begin{tabular}{|c|l|l|c|l|l|}
\hline S.No & \multicolumn{1}{|c|}{ Specifications } & \multicolumn{1}{c|}{ Values } & S.No & \multicolumn{1}{c|}{ Specifications } & \multicolumn{1}{c|}{ Values } \\
\hline 1. & Number of DC motors & 01 & 9. & Maximum phase current & $110 \mathrm{amp}$ \\
\hline 2. & Direction of motor & Both way & 10. & Rated torque & $113 \mathrm{Nm}$ \\
\hline 3. & Gears in motor & 01 & 11. & Rated phase current & $110 \mathrm{amp}$ \\
\hline 4. & Weight of motor & $06 \mathrm{~kg}$ & 12. & No of pole & 06 \\
\hline 5. & Input DC link voltage & 240 Volts & 13. & Permanent magnet flux & 0.07 \\
\hline 6. & Maximum output power & $850 \mathrm{watt}$ & 14. & No of stator slot & 57 \\
\hline 7. & Maximum torque & $220 \mathrm{~N}$ & 15. & Switching frequency & 08 \\
\hline 8. & Motor maximum speed & $3000 \mathrm{rpm}$ & & & \\
\hline
\end{tabular}

Table-4 Gear-1 Specification

\begin{tabular}{|c|l|l|c|l|l|}
\hline S.No & \multicolumn{1}{|c|}{ Specifications } & \multicolumn{1}{c|}{ Values } & S.No & \multicolumn{1}{c|}{ Specifications } & Values \\
\hline 1. & Diameter of gear 1 & $30 \mathrm{~mm}$ & 7. & Addendum & $1 \mathrm{~mm}$ \\
\hline 2. & Teeth & 16 & 8. & Dedendum & $1.25 \mathrm{~mm}$ \\
\hline 3. & Tangential load & $609 \mathrm{~N}$ & 9. & Depth of teeth & $2.25 \mathrm{~mm}$ \\
\hline 4. & Static load & $401.82 \mathrm{~N}$ & 10. & Velocity of gear & $3 \mathrm{~m} / \mathrm{s}$ \\
\hline 5. & Working load & $477.3 \mathrm{~N}$ & 11. & R.P.M & 3000 \\
\hline 6. & Internal dia & $20 \mathrm{~mm}$ & & & \\
\hline
\end{tabular}

Table-5 Gear-2 Specification

\begin{tabular}{|c|l|l|c|l|l|}
\hline S.No & \multicolumn{1}{|c|}{ Specifications } & \multicolumn{1}{c|}{ Values } & S.No & \multicolumn{1}{c|}{ Specifications } & \multicolumn{1}{c|}{ Values } \\
\hline 1. & Diameter of gear 2 & $68 \mathrm{~mm}$ & 7. & Addendum & $1 \mathrm{~mm}$ \\
\hline 2. & Teeth & 52 & 8. & Dedendum & $1.25 \mathrm{~mm}$ \\
\hline 3. & Tangential load & $172 \mathrm{~N}$ & 9. & Depth of teeth & $2.25 \mathrm{~mm}$ \\
\hline 4. & Static load & $362.67 \mathrm{~N}$ & 10. & Velocity of gear & $3.13 \mathrm{~m} / \mathrm{s}$ \\
\hline 5. & Working load & $1045 \mathrm{~N}$ & 11. & R.P.M & 923 \\
\hline 6. & Internal dia & $17 \mathrm{~mm}$ & & & \\
\hline
\end{tabular}


IOSR Journal of Mechanical and Civil Engineering (IOSR-JMCE)

e-ISSN: 2278-1684, p-ISSN: 2320-334X

Table-6 Gear-3 Specification

\begin{tabular}{|c|l|l|c|l|l|}
\hline S.No & \multicolumn{1}{|c|}{ Specifications } & \multicolumn{1}{c|}{ Values } & S.No & \multicolumn{1}{|c|}{ Specifications } & \multicolumn{1}{c|}{ Values } \\
\hline 1. & Diameter of gear 3 & $36 \mathrm{~mm}$ & 7. & Step-2 Dia of gear shaft & $12 \mathrm{~mm}$ \\
\hline 2. & Teeth & 23 & 8. & Addendum & $1.176 \mathrm{~mm}$ \\
\hline 3. & Tangential load & $354 \mathrm{~N}$ & 9. & Dedendum & $1.47 \mathrm{~mm}$ \\
\hline 4. & Static load & $620.36 \mathrm{~N}$ & 10. & Depth of teeth & $2.6 \mathrm{~mm}$ \\
\hline 5. & Working load & $797 \mathrm{~N}$ & 11. & Velocity of gear & $1.6 \mathrm{~m} / \mathrm{s}$ \\
\hline 6. & Step-1 Dia of gear shaft & $17 \mathrm{~mm}$ & 12. & R.P.M & 923 \\
\hline
\end{tabular}

Table-7 Gear-4 Specification

\begin{tabular}{|c|l|l|c|l|l|}
\hline S.No & \multicolumn{1}{|c|}{ Specifications } & \multicolumn{1}{c|}{ Values } & S.No & \multicolumn{1}{c|}{ Specifications } & \multicolumn{1}{c|}{ Values } \\
\hline 1. & Diameter of gear 1 & $110 \mathrm{~mm}$ & 7. & Addendum & $1.176 \mathrm{~mm}$ \\
\hline 2. & Teeth & 71 & 8. & Dedendum & $1.47 \mathrm{~mm}$ \\
\hline 3. & Tangential load & $962.75 \mathrm{~N}$ & 9. & Depth of teeth & $2.6 \mathrm{~mm}$ \\
\hline 4. & Static load & $465 \mathrm{~N}$ & 10. & Velocity of gear & $1.6 \mathrm{~m} / \mathrm{s}$ \\
\hline 5. & Working load & $2037 \mathrm{~N}$ & 11. & R.P.M & 300 \\
\hline 6. & Internal dia & $30 \mathrm{~mm}$ & & & \\
\hline
\end{tabular}

Table-8 Coupling specifications

\begin{tabular}{|c|l|l|c|l|l|}
\hline S.No & \multicolumn{1}{|c|}{ Specifications } & \multicolumn{1}{|c|}{ Values } & S.No & \multicolumn{1}{|c|}{ Specifications } & \multicolumn{1}{c|}{ Values } \\
\hline 1. & Inner dia. of coupling for shaft & $17 \mathrm{~mm}$ & 4. & Thickness of flange & $5 \mathrm{~mm}$ \\
\hline 2. & Outer dia. of hub & $30 \mathrm{~mm}$ & 5. & Dia.of hole for bolts & $3 \mathrm{~mm}$ \\
\hline 3. & Outer dia. Of flange & $71 \mathrm{~mm}$ & 6. & No. of bolts & $6 \mathrm{No}$. \\
\hline
\end{tabular}

\section{ANALYSIS}

The static structural analysis of gears was done in ANSYS 14.0 version and all the designing work was done in SOLIDWORKS. Analysis was done of the following parts...
A.Gear-1 Analysis
B. Gear-2 Analysis
C. Gear-3 Analysis
D. Gear-4 Analyses
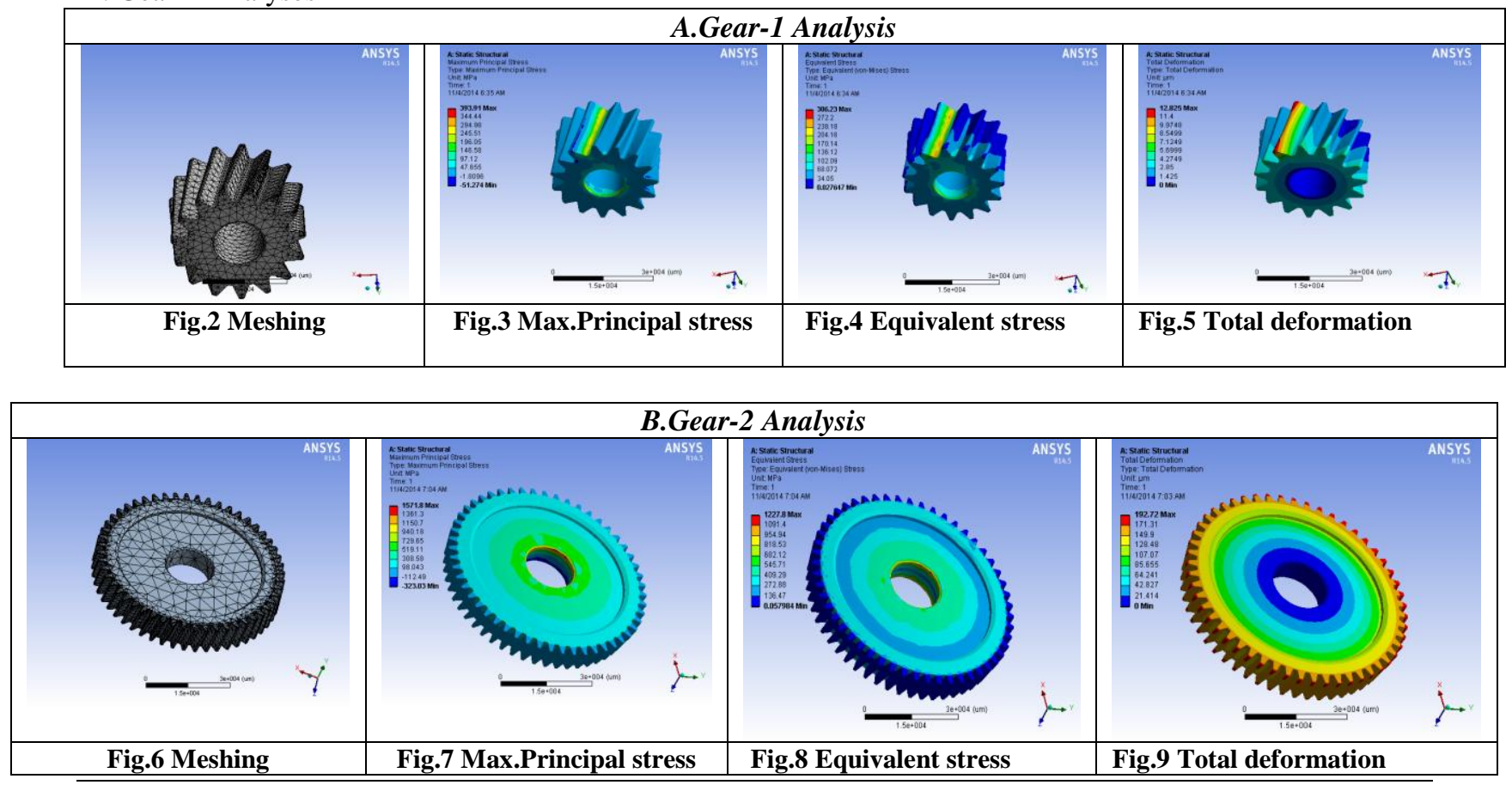


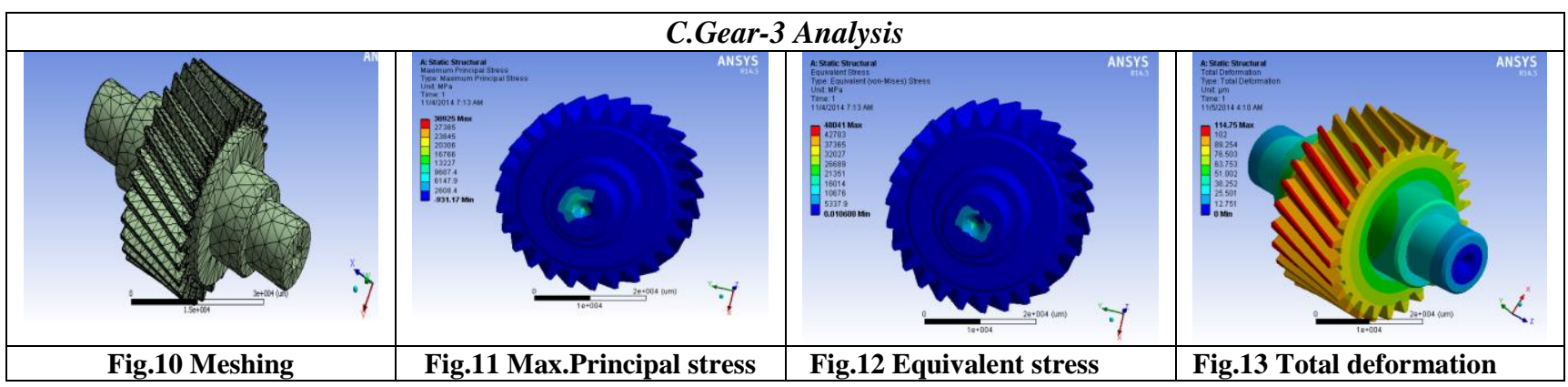

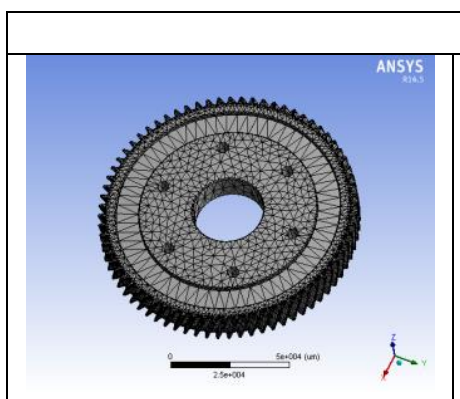

Fig.14 Meshing

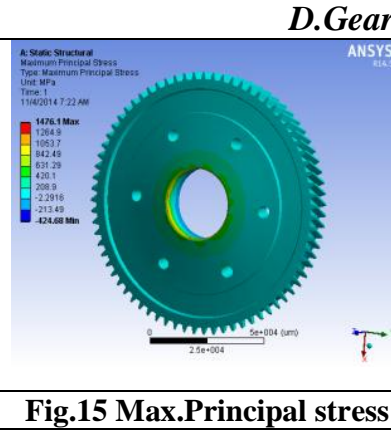

VII.

RESULT OF ANALYSIS

Table-9. FOR GEAR-1

\begin{tabular}{|c|l|l|c|l|l|}
\hline S.No & \multicolumn{1}{|c|}{ Specifications } & \multicolumn{1}{|c|}{ Values } & S.No & \multicolumn{1}{c|}{ Specifications } & \multicolumn{1}{c|}{ Values } \\
\hline 1. & Magnitude & $75 \mathrm{MPa}$ & 6. & Min.Equivalent stress & $0.02764 \mathrm{MPa}$ \\
\hline 2. & No of Nodes & 35285 & 7. & Max.Equivalent stress & $306.23 \mathrm{MPa}$ \\
\hline 3. & No of Elements & 19709 & 8. & Min deformation & $0 \mu \mathrm{m}$ \\
\hline 4. & Min.Principal stress & $-51.274 \mathrm{MPa}$ & 9. & Max. deformation & $12.82 \mu \mathrm{m}$ \\
\hline 5. & Max.Principal stress & $393.91 \mathrm{MPa}$ & & & \\
\hline
\end{tabular}

Table-10 FOR GEAR-2

\begin{tabular}{|c|l|l|c|l|c|}
\hline S.No & \multicolumn{1}{|c|}{ Specifications } & \multicolumn{1}{|c|}{ Values } & S.No & \multicolumn{1}{c|}{ Specifications } & \multicolumn{1}{c|}{ Values } \\
\hline 1. & Magnitude & $75 \mathrm{MPa}$ & 6. & Min.Equivalent stress & $0.0579 \mathrm{MPa}$ \\
\hline 2. & No of Nodes & 103400 & 7. & Max.Equivalent stress & $1227.8 \mathrm{MPa}$ \\
\hline 3. & No of Elements & 59482 & 8. & Min deformation & $0 \mu \mathrm{m}$ \\
\hline 4. & Min.Principal stress & $-323.0 \mathrm{MPa}$ & 9. & Max. deformation & $192.72 \mu \mathrm{m}$ \\
\hline 5. & Max.Principal stress & $1571.8 \mathrm{MPa}$ & & & \\
\hline
\end{tabular}

Table-11 FOR GEAR-3

\begin{tabular}{|c|l|l|c|l|l|}
\hline S.No & \multicolumn{1}{|c|}{ Specifications } & \multicolumn{1}{|c|}{ Values } & S.No & \multicolumn{1}{c|}{ Specifications } & \multicolumn{1}{c|}{ Values } \\
\hline 1. & Magnitude & $75 \mathrm{MPa}$ & 6. & Min.Equivalent stress & $0.0106 \mathrm{MPa}$ \\
\hline 2. & No of Nodes & 71436 & 7. & Max.Equivalent stress & $480.41 \mathrm{MPa}$ \\
\hline 3. & No of Elements & 41685 & 8. & Min deformation & $0 \mu \mathrm{m}$ \\
\hline 4. & Min.Principal stress & $-931.1 \mathrm{MPa}$ & 9. & Max. deformation & $114.75 \mu \mathrm{m}$ \\
\hline 5. & Max.Principal stress & $309.25 \mathrm{MPa}$ & & & \\
\hline
\end{tabular}


Table-12 FOR GEAR-4

\begin{tabular}{|c|l|l|c|l|l|}
\hline S.No & \multicolumn{1}{|c|}{ Specifications } & \multicolumn{1}{|c|}{ Values } & S.No & \multicolumn{1}{c|}{ Specifications } & \multicolumn{1}{c|}{ Values } \\
\hline 1. & Magnitude & $75 \mathrm{MPa}$ & 6. & Min.Equivalent stress & $0.0166 \mathrm{MPa}$ \\
\hline 2. & No of Nodes & 138515 & 7. & Max.Equivalent stress & $1154.7 \mathrm{MPa}$ \\
\hline 3. & No of Elements & 78833 & 8. & Min deformation & $0 \mu \mathrm{m}$ \\
\hline 4. & Min.Principal stress & $-424.68 \mathrm{MPa}$ & 9. & Max. deformation & $30.191 \mu \mathrm{m}$ \\
\hline 5. & Max.Principal stress & $1476.1 \mathrm{MPa}$ & & & \\
\hline
\end{tabular}

VIII. CONCLUSION

As there is always an upcoming day to day in automobile industry with the evolution of new ideas and new technologies. Today's main aim of all automobile industry is to reduces the level of harmful gases to as much low level as it can be which is pollution not only plants and human beings but in turn creating a green house effect also. For this very reason blames always come upon all types of internal combustion engines. But to cover this side effect electric vehicles are coming in parallel path to achieve a pollution free environment.

In this paper many good effects of electric vehicles have been discussed, from environmental point of view and the research presented here shall be a type of bench work for all of us. Here all aspects have been discussed in detail about the electric vehicles, like what is the main basic principal of electric vehicles, there complex and simplex nature and use of batteries, etc. What would be cost criteria? And what shall be its side effects on our environment. More over the gears which were used for transmission of power from motor to the wheels were also analyzed and had proved to be satisfactory.

1. Cars developers have made very much costlier electronic components which they have fitted in their vehicles whereas; we have reduced the cost of electronics components.

2. Only passenger type have made, whereas we made it suitable for re utility, either it may be passenger type or loader type or use for teenager or by a very old person who can afford to put his leg down and handle in crowed space.

3. All the solar electric vehicles are fitted with accelerator in their hand where as we have made it fitted in foot. Motor is not fitted directly with the tires, but with differential so as to facilitate while turning.

4. This vehicle may be used as a passenger vehicle along with loader vehicle.

5. This vehicle can be used as a spying vehicle where silence is needed for spying purpose.

6. This vehicle may be used in case if a fuel crisis as it is fitted with recyclable and rechargeable batteries.

7. It is an eco-friendly vehicle as no pollution is being omitted as this car is not having internal combustion engine.

8. Almost $100 \%$ of these batteries can be recycled, which keeps old batteries from becoming a disposal problem.

9. It is easy to drive as it is gearless drive.

10. It uses the energy as solar energy to charge the batteries.

11. Motor can run in both the directions, ie. Forward and in reverse direction.

12. It can run a stretch of $125 \mathrm{KM}$ approximately with a single shot of charge to the batteries of at least, 3-4 hours at a charging value of 3 amperes.

13. It can carry a weight of more than $1100 \mathrm{~kg}$ of weight.

\section{ACKNOWLEDGEMENT}

We are highly thankfull to the Management of Gulzar Group of Institutes, Ludhiana for providing us Research and Development facility in this Institute due to which it has been possible to design and develop this very project. We are highly thankfull, especially to our Executive Director, Er.Gurkirat Singh Ji for helping us by all means and we are also thankful to our campus Director Prof.Dr.Vijay Athawale for encouraging us in every field. 


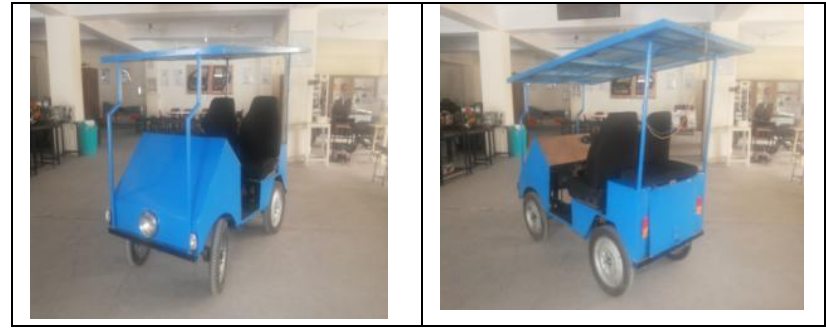

\section{REFERENCES}

[1]. C.C. Chan and K.T. Chau, Modern Electric Vehicle Technology, Oxford University Press, New

York, 2001.

[2]. K.M. Rahman and M. Ehsani, Performance analysis of electric motor drives for electric and application, IEEE Power Electronic in Transportation, 29-26, 1996.

hybrid electric vehicle

[3]. Y. Gao, H. Maghbelli, M. Ehsani, et al., Investigation of proper motor drive characteristics for Society of Automotive Engineers (SAE) Journal, Paper No. 2003- 01-2296, Warrendale, PA, 2003.

[4]. Z. Rahman. M. Ehsani, and K. Butler, An investigation of electric motor drive characteristics systems, Society of Automotive Engineers (SAE) Journal, Paper No.2000-01-3062, Warrendale, PA, 2003.

[5] .Z. Rahman, M. Ehsani, and K. Butler, Effect of extended-speed, constant-power operation of and performance of EV-HEV propulsion system, Society of Automotive Engineers (SAE) Journal, Paper No. 2000-01-1227 , Warrendale, PA, 2003.

[6]. D.A.J. Rand, R. Woods, and R.M. Dell, Batteries for Electric Vehicles, Research Studies Press, United Kingdom, 1998.

[7]. Y. Gao, H. Maghbelli, M. Ehsani, et al., Investigation of proper motor drive characteristics for Society of Automotive Engineers (SAE) Journal, Paper No. 2003- 01-2296, Warrendale, PA, 2003.

Ltd.,Baldock, Hertfordshire, military vehicle propulsion, 